\title{
Neandertal signatures in modern human mitochondrial genome haplogroups?
}

Authors

Renata C. Ferreira $^{1 *}$, Camila R. Rodrigues ${ }^{2 *}$, James R. Broach ${ }^{3}$ and Marcelo R. S. Briones ${ }^{4 *}$

\author{
Affiliations \\ ${ }^{1}$ Department of Neurology and Neurosurgery, Federal University of São Paulo, São \\ Paulo, SP, Brazil, CEP 04039032. \\ ${ }^{2}$ Graduate Program in Microbiology and Immunology, Federal University of São Paulo, \\ São Paulo, SP, Brazil, CEP 04039032. \\ ${ }^{3}$ Institute for Personalized Medicine, Department of Biochemistry, Pennsylvania State \\ University College of Medicine, 500 University Drive, 17033, Hershey PA, USA. \\ ${ }^{4}$ Department of Health Informatics, Federal University of São Paulo, São Paulo, SP, \\ Brazil, CEP 04039032.
}

*Both share first author status

*Corresponding author: Marcelo R. S. Briones

Escola Paulista de Medicina - UNIFESP, Edifício de Pesquisas II, L4E

Rua Pedro de Toledo, 669, CEP 04039-032, São Paulo, SP, Brazil. Tel: +55 11 5576-

4537. E-mail: marcelo.briones@ unifesp.br and briones.marcelo.rs@gmail.com

\section{Short title: Neandertal signatures in human mtDNA}




\section{Abstract}

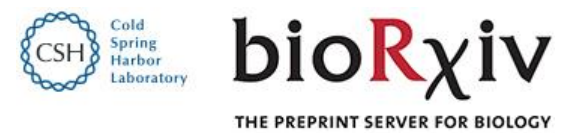

Genetic contributions of Neandertals to the modern human genome have been evidenced by comparative analyses of present day human genomes and paleogenomes. The current data indicates that Neandertal introgression is higher in Asians and Europeans and lower in African lines of descent. Neandertal signatures in extant human genomes are attributed to intercrosses between Neandertals and ancient Homo sapiens lineages, or archaic Anatomically Modern Humans (AMH) that migrated from Africa into the Middle East and Europe in the last 50,000 years. It has been proposed however that there is no contribution of Neandertal mitochondrial DNA to contemporary human genomes. Here we show that the modern human mitochondrial genome might contain potential 66 Neandertal signatures, or Neandertal single nucleotide variants (N-SNVs) of which 7 are associated with traits such as cycling vomiting syndrome and Alzheimers' and Parkinsons' diseases and 2 N-SNVs associated with intelligence quotient. Principal component analysis and bootscan tests suggest rare recombination events. Also, contrary to what is observed in the nuclear genome, African mitochondrial haplogoups have more potential Neandertal signatures than Asian and European haplogroups. Based on our results we hypothesize that although most intercrosses occurred between Neandertal males and archaic AMH females, crosses between archaic AMH males and Neandertal females were extremely rare and with rare recombination events thus leaving few marks (66 out of 16,569bp) in present day mitochondrial genomes of human populations.

\section{Introduction}

Comparative analyses of present day human genomes and paleogenomes led to the proposal that Neandertals contributed to the modern makeup of the human genome (Green et al., 2010; Ko, 2016; Prüfer et al., 2014; Simonti et al., 2016). The current interpretation of genomic signatures is that Neandertal contributions are different in European, East Asian and African lines of descent, with a higher frequency of Neandertal segments in Asians and Europeans and lower frequencies in Africans (Green et al., 2010). Intercrosses between Neandertals and ancient Homo sapiens lineages, or archaic Anatomically Modern Humans (AMH) who migrated from Africa into the Middle East and Europe in the last 50,000 years might explain the presence of Neandertal signatures in extant human genomes (Prüfer et al., 2014; Simonti et al., 2016). The spatio-temporal overlap of Neandertals and AMH is estimated to be approximately 22,000 years since the first AMH arrived in Europe around 50,000 years ago and the last Neandertal remains (in Spain) date back to 28,000 years (Gibbons, 2010; Higham et al., 2014).

Although there is evidence for Neandertal contributions to the modern nuclear genome, it has been proposed that there is no Neandertal contribution to contemporary human mitochondrial genomes (mitogenomes) (Serre et al., 2004). Because of mitogenome matrilineal inheritance this implies that the intercrosses occurred exclusively between Neandertal males and AMH females or that crosses between AMH males and Neandertal females were extremely rare. Another possibility is that crosses between AMH males and Neandertal females produced such unfavorable trait combinations, due to mitonuclear incompatibility (Hill and Johnson, 2013), that none of their descendants left marks in present day human populations. 


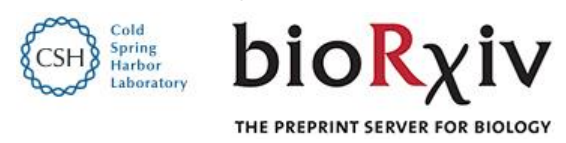

To address this problem we searched for mitochondrial single nucleotide variants (SNVs), or signatures, in contemporary human mitogenomes that were also present in Neandertals but not in archaic AMH mitogenomes. For this we selected archaic AMH samples with approximately the same age as Neandertal mitogenomes, thus representing, in theory, an archaic AMH ensemble that could have overlapped with Neandertals in Europe, Middle East and Central Asia. This also might alleviate the effect of homoplasies because Neanderthal and archaic AMH sequences have approximately the same age.

\section{Results}

\section{Distribution of Neandertal SNVs}

An alignment of 102 sequences was produced which contained the mitogenomes of 41 archaic AMH (Table 1), 9 Homo sapiens neanderthalensis (Table 1) and 52 contemporary Homo sapiens sapiens with representatives of the major worldwide mitochondrial haplogoups (table S1). This alignment contained the revised Cambrige Reference Sequence (rCRS) used as numbering reference for all polymorphisms identified (Andrews et al., 1999). We found 66 positions in which contemporary Homo sapiens sapiens were identical with at least one Homo sapiens neanderthalensis sequence position (Fig. 1, Supplementary Tables S2 and S3). In 13 positions just a subset of contemporary Homo sapiens sapiens were identical with at least one Homo sapiens neanderthalensis sequence position and at least one sequence of archaic AMH. In 175 positions Homo sapiens neanderthalensis differed from contemporary Homo sapiens sapiens and archaic AMH. In 11 positions the archaic AMH differed from other sequences and in 653 positions the contemporary Homo sapiens sapiens presented expected variants among haplogroups that were not relevant for this analysis. The total variants are detailed in data S1.

To depict the distribution of Neandertal SNVs, or N-SNVs, in different human mitochondrial haplogroups, we constructed a heat map of N-SNVs (Fig. 2). Most N-SNVs are concentrated in the D-loop, followed by 12SrDNA and 16SrDNA. Among tRNAs N-SNVs were found only in isoleucine, asparagine and cysteine tRNAs. In COX2 only one N-SNV was found in haplogroup R0a.

Of the $66 \mathrm{~N}-\mathrm{SNV}$ s identified, 20 are common to modern African and Eurasian haplogroups, 25 are exclusive to African haplogroups and 21 are exclusive to Eurasian haplogroups. In Fig. 3 the distribution of N-SNVs is depicted in the human mitogenome map. The distribution reveals that 11 Eurasian N-SNVs are in coding regions, 3 in rRNA genes and 1 in a tRNA gene.

The distribution of N-SNVs in modern haplogroups and archaic AMH can be summarized as possible six introgression routes with predicted consequences (Fig. 4). In hypothesis (1) SNVs conserved between Neandertals, archaic AMH and present day humans should be observed in all sequences; in (2) if the introgression crosses occurred between Neandertals and archaic AMH prior to divergence that separated archaic AMH from lineages of African and Eurasian haplogroups it is expected that N-SNVs would be present in all sequences, as observed for $13 \mathrm{~N}$-SNVs. In (3) the crosses would have occurred only with 


\section{오를 bioRXiv}

archaic AMH who did not contribute to present day haplogroups while hypotheses (4), (5) and (6) would represent crosses between Neandertals and lineages who contributed to present day haplogroups. The $66 \mathrm{~N}-\mathrm{SNV}$ s are consistent with these hypotheses, which exclude their presence in archaic AMH and thus are likely signals of crosses between these two human subspecies. More importantly no SNVs are identical between Neandertals and archaic AMH at the exclusion of present day mitogenomes of either African and Eurasian haplogroups which suggests that the presence of N-SNVs must be a signal of horizontal transfer or a very high number of reverse/convergent substitutions.

\section{Disease associated N-SNVs}

Among the $66 \mathrm{~N}-\mathrm{SNVs}, 7$ are associated with diseases as depicted in Table 2. Of note 4 of these disease associated N-SNVs were observed in African haplogroups (L0, L1, L2, L3, L4, L5 and L6) and 3 were observed exclusively in Eurasian haplogroups. The most common diseases associated with $\mathrm{N}-\mathrm{SNV}$ s are neurological disorders and tumors. One N-SNVs, in position 15,043 and associated with depression, was also found in one archaic AMH. Although not considered a bona fide N-SNV based on our exclusion criteria, it is relevant because chronic depression has been associated with Neandertal introgression (Racimo et al., 2017). Among protein coding genes an important N-SNV was found in ND2 (position 5,460) causing an amino acid change from alanine to threonine that has been associated with Alzheimers' and Parkinsons' diseases due to its high prevalence in the brains of Alzheimers' and Parkinsons' patients (Lin et al., 1992; Petruzzella et al., 1992; Schnopp et al., 1996). This amino acid substitution changes a nonpolar amino acid to a polar amino acid, which promotes destabilizing effects in the encoded NADH dehydrogenase. Nonpolar to polar amino acid changes are associated with amyloid diseases (Alvares et al., 2013; Podoly et al., 2010; Volkenstein, 1965). Other disease associated N- SNVs are located in the D-loop, 16S rRNA and tRNA-Cys (Table 2). The prevalence of diseases associated with N-SNVs in Table 2 are: Bipolar disorder $=596$ cases in 100,000 persons $(596 / 100,000)$ (GBD Compare | IHME Viz Hub), Cycling vomiting syndrome 3.2/100,000 (Fitzpatrick et al., 2008), Parkinsons' disease $=111 / 100,000($ GBD Compare $\mid$ IHME Viz Hub), Alzheimers' disease $=588 / 100,000(\mathrm{GBD}$ Compare | IHME Viz Hub), Melanoma $=30.42 / 100,000$ (GBD Compare | IHME Viz Hub), Deafness $=110 / 1,000$ (Lancet, 2016), Glioblastoma $=10 / 100,000$ (Hanif et al., 2017), Ovarian cancer $=17.71 / 100,000($ GBD Compare $\mid$ IHME Viz Hub), Lung cancer $=$ 43/100,000 (GBD Compare | IHME Viz Hub), Prostate cancer $=129 / 100,000$ (GBD Compare | IHME Viz Hub), Stomach cancer $=36.9 / 100,000($ GBD Compare $\mid$ IHME Viz Hub).

\section{Haplogroups of paleogenomes}

Mitogenomes of Neandertals and archaic AMH were classified in haplogroups according to sequence similarity with extant human mitogenomes using Haplogrep 2 (Weissensteiner et al., 2016) (Table 1). 83\% of archaic AMH mitogenomes belong to haplogroup U (45\% haplogroup U5 and 16\% to haplogroup U2) which is consistent as U being the oldest European haplogroup. Among the 9 Neandertal mitogenomes, the 7 more recent genomes can be classified as haplogroup H1 (European) while the two oldest can be classified as haplogroup L (African) (Table 2). N-SNVs at positions 16,278 and 16,298 are associated with intelligence quotient (Thomas et al., 1998). N-SNV 16,278 is found in African haplogroups (L0, L1, L2, L5 and L6) and two Eurasian haplogroups (X3, U2c and P2) and in all Neandertal sequences while N-SNV 16.298 is found only in Eurasian-Native American haplogroups (V1, V2, M8, C1, C4, C7 and Z1) and only in the Altai Neandertal. 


\section{PCAs of Neandertal and Human mitogenomes}

Principal component analysis (PCA) of the whole mitochondrial genome shows four clusters: (1) the modern haplogroups including the ancient $H$. sapiens (Table 2), (2) the L haplogroup cluster, (3) the Neandertal Altai-Mezmaskaya L-like cluster (Table 2) and (4) the Neandertal H-like group (Fig. 5). However the PCA of the segment corresponding to the ribosomal RNA gene proximal half produces a pattern that approximates the L haplogroup cluster to the Neandertal Altai-Mezmaskaya L-like cluster suggesting the introgression point. The PCA of ribosomal RNA gene distal half suggests an opposite pattern with L cluster closer to Neandertal although not as close as shown in Fig. 5B.

\section{Bootscan analysis of mitogenomes}

We tested potential recombination in our dataset with bootscan. We used a different set of parental sequences depending on the query mitogenome (Fig. 6). The bootscan analysis indicates that there are potential recombination points. Upon deeper analysis we observed that bootscan considers the Neandertal specific signatures, such as in L haplogroups, as recombination points. Although the bootscan putative recombination segments are above the bootstrap threshold we do not consider this as definitive evidence of recombination since the segments between the Neandertal signatures are almost identical. Bootscan analysis did exclude Human-Neandertal recombintation in rCRS sequence (Supplementary Fig. S1). Sensivity of bootscan to substitution models and alignment methods was assessed by comparing the same set query-parentals with different parameters (Supplementary Fig. S2), revealing minor profile alterations. The alignment parameters are not so critical in this case because the sequences are extremely conserved (918 polymorphic positions in 16,565bp). Although indels are present in the alignments, $99 \%$ are located near the $\mathrm{H}$ promoter in the Dloop region. These are automatically excluded in phylogeny inference algorithms and therefore have no weight in bootscan results. The "positional homology" is therefore solid, particularly in coding domains and regions without repeats in non-coding domains. The Neandertal signatures are in unambiguously aligned segments.

\section{Discussion}

In this present study we propose the hypothesis that there are Neanderthal signatures in modern human mitochondrial genome and our recombination test data (bootscan analysis) suggests that recombination might explain the presence of these SNVs, which we called NSNVs in these genomes. We construed our hypothesis based on an alignment of 102 mitogenomes which contained 918 polymorphic positions. The mitogenomes analysed were from modern Homo sapiens, Archaic Anatomically modern humans and Neanderthals as detailed above. Based on populational data Sykes (2001) estimated that a single observed change in comparative mitogenomics corresponds to 10,000 years of divergence. More modern estimates of the mitogenome clock, based on ancient DNA data, ranges from $2.14 \times 10^{-8}$ to $2.74 \times 10^{-8}$ substitutions per site per year (Fu et al., 2013, 2014; Posth et al., 2016; Rieux et al., 2014), which gives approximately 4.14 substitutions in mitogenomes in 10,000 years. Therefore according to populational estimates the 918 polymorphisms would have occurred in a period of 9.18 million years and the $66 \mathrm{~N}-\mathrm{SNV}$ s during 660,000 years. If ancient DNA estimates are considered the 918 polymorphisms would correspond to 2.21 million years of evolution and the $66 \mathrm{~N}-\mathrm{SNVs}$ would have occurred in the last 159,420 years. 


\section{이를 bioRXiv}

The problem here is that even if we assume that all $66 \mathrm{~N}-\mathrm{SNV}$ s are a product of random changes or simple homoplasies how come they did not occur in any of the 41 samples of archaic AMH? We would have to assume that only in the modern lineage homoplasies, parallel with Neandertals, would be observed and none of those observed in archaic AMH. Therefore we tested for recombination using boostscan (Fig. 6). These tests indicate that in 11 positions the boostrap support is significant for recombination. Therefore the hypothesis alternative to homoplasies-only hypothesis is supported by data. It is important to notice that Posada and Crandall (Posada and Crandall, 2001) explicitly tested how homoplasies could "confound" recombination tests and concluded that only in extreme levels of rate variation $(\alpha=0.05)$ recombination tests would produce false positives. Our work is a hypothesis and theory study and does not aim to provide a final answer to the 66 positons that are identical in modern humans and Neandertal at the complete exclusion of all 41 archaic AMH here analysed. We believe that assuming that all the $66 \mathrm{~N}-\mathrm{SNV}$ are purely a product of homoplasies is simplistic and places the "burden of the proof" in the proponents of the homoplasies-only hypothesis to demonstrate that all 66 positions are homoplasic and that exactly how these homoplasies would have produced artifacts in the bootscan analysis. $H$. sapiens emerged around 300,000 years ago, likely derived from Homo heidelbergensis, which is consistent with the divergence time frames estimated from our mitogenome data.

Also, the analysis of Neandertal mitochondrial genomes revealed four derived aminoacid changes that modern humans carry in the COX2 gene as compared to Neanderthals and other Ape outgroups (Green et al., 2008). However, the same four amino-acid changes can also be found in macaques. Based on this argument it has been proposed that there is no need to "invoke" mitochondrial recombination, which is exceedingly rare, if present at all, or interbreeding events to explain the presence of N-SNVs in modern human mitochondrial genomes and therefor recurrent mutations would be sufficient to explain N-SNVs. We contend that the argument above against any recombination, which would lead to a allhomoplasies hypothesis, is problematic since the divergence between the H. sapiens lineage and macaques lineage is 42.9 million years (Steiper and Young, 2006) while the divergence we are observing here is between 300,000 to 28,000 years and as is widely known, homoplasies increase significantly with long divergences. This produces the effect of long branch attraction in phylonenies (Bergsten, 2005). For example one of the mutations "macaques" parallel mutation is the $\mathrm{m} .7650 \mathrm{C}>\mathrm{T}$ in the COX2 gene. This mutation is found in Neandertals (except Mezmaskaya), Denisovans, modern R0 haplogroup, Gorilla, Chimpanzee and Bonobo. It was not found in any archaic human samples. This pattern suggests more likely that it is highly conserved, inherited by early hominins from apes and secondarly lost in one Neandertal lineage and in almost all Homo sapiens lineages, expect for the R0 haplogroup. The reapearance of this mutation in the very old R0 haplogroup has two possible explanations: (1) a back mutation reverting to exact the same ancestral condition instead of changinf to any of the other three possible bases or (2) acquired by recombination via a Neandertal female introgressed in one of the Homo sapiens lineages. The referee criticism is highly argumentative and no quantitative data is presented to show that hypothesys $\mathrm{H}_{(1)}$ has more likelihood than hypothesis $\mathrm{H}_{(2)}$. In our manuscript we present a bootstrap recombination analysis (bootscan) that curiouly show (Fig. 6A, 6E and 6F) that a recombination point has bootstrap support in the region emcompassing m.7650C $>$ T. From this test it seems that hypothesis $\mathrm{H}_{(2)}$ has more statistical support than $\mathrm{H}_{(1)}$. So far we found no published statistical evidence that presents quantitative evidence that contradicts our findings and therefore a homplasies-only hypothesis is not supported. In addition our present work does not "invoke" 


\section{오를 bioRXiv}

recombination or propose as a mere explanatory argument, it has been explicitly tested by bootscan and supports the clusters identified by PCA (Fig. 5 and 6).

Another possible argument is that the Neandertal signatures are in fact character states conserved since the last common ancestor of Neandertals and present day Homo sapiens (e.g. Homo erectus but this would not be consistent with the absence of these signatures in ancient H. sapiens mitochondrial genomes (Fig. 1). Alternatively, the Neandertal signatures here described could be a consequence of random events. The chance that the 66 positions are simultaneously identical by chance alone would be roughly $0.25^{66}\left(1.84 \times 10^{-40}\right)$ which is far less than observed here.

In regard to presence of N-SNVs in African haplogroups it is interesting to note that a back to Africa hypothesis has been proposed in which humans from Eurasia returned to Africa and impacted a wide range of sub-Saharan populations (Henn et al., 2012). Our data suggest that Neandertal signatures might be present in all major African haplogroups which is consistent with the "Back to Africa" contribution to the modern mitochondrial African pool. The preponderance of N-SNVs in the D-loop is observed mostly in African haplogroups. In Eurasian haplogroups we observe important changes in coding regions as demonstrated in Fig. 2 and 3. Also the recombination tests here used were demonstrated to provide false positives only when rate heterogeneity is higher than the observed in our data. Mitochondrial recombination is not so rare as to completely exclude it as a potential mechanism to explain the 66 N-SNVs here observed (D’Aurelio et al., 2004; Mita et al., 1990).

Our observations suggest that crosses between AMH males and Neandertal females left significantly less descendants than the reverse crosses (Neandertal males and AMH females), which seems to be the dominant pattern. Although it has been generally accepted that recombination does not occur in the human mitochondrial genome, evidence of mitochondrial recombination has been reported (Kraytsberg et al., 2004; Schwartz and Vissing, 2002). A scenario with complete absence of recombination presents a problem to explain how the human mitochondrial genome would escape the Muller's ratchet and therefore avoiding its predicted "genetic meltdown" (Felsenstein, 1974). It has been shown that even minimal recombination is sufficient to allow the escape from the Muller's ratchet (Dokianakis and Ladoukakis, 2014) and this could be the case of the human mitochondrial genome. For example, recombination has been simulated along a chromosome of 1000 loci to estimate the amounts of recombination required to halt Muller's ratchet and the drift-catalysed fixation of deleterious mutations. It has been found that for a population size of $N<100$, a recombination rate equivalent to one crossover per chromosome per 100 generations $\left(10^{-5} /\right.$ locus/generation $)$ countered Muller's ratchet effectively. This is much lower than the minimum of one crossover per chromosome arm per generation that is assumed to occur in sexual taxa. A higher recombination rate of $10^{-4}$ can impede the selective interference that would otherwise enhance the fixation of deleterious mutations due to genetic drift (Neiman and Taylor, 2009).

Our data is compatible with a scenario in which the AMH-Neandertal crosses occur in Europeans, East Asians and African lines of descent. However, in the African haplogroups the crosses between AMH males and Neandertal females would have a higher frequency than in European lines of descent, where the reverse crosses would be predominant. Based on the comparison of Neandertal signatures in nuclear and mitochondrial genome haplogroups we hypothesize that the African lines of descent would have a higher female Neandertal 


\section{일 bioRxiv}

contribution whereas European lines of descent would have higher male Neandertal contribution. The fact that AMH and Neandertals crossed and produced fertile descendants is evidence that they belong to the same species (Ko, 2016) and thus indicate that Homo sapiens emerged independently in Africa, Europe and Asia (Horai et al., 1995). The intercrosses of these three Homo sapiens subgroups, and other even deeper ancestors such as Denisovans, in its different proportions and specific signatures, would have produced the extant human genomes.

The analyses here presented suggest that Neandertal genomic signatures might have been a product of rare mtDNA recombination events. Although there is evidence for mtDNA recombination, its weight in phylogenies and mutational patterns in comparative analysis remain controversial. Some authors contend that due to its high mutation rate reverse compensatory mutations can be confounded with recombination in mtDNA. Our data is consistent with a scenario in which mtDNA recombination occurred. These recombination events were probably extremely rare which might explain the observed small number of potential Neandertal signatures in modern human mitochondrial genomes.

\section{Materials and Methods}

\section{Experimental Design}

Comparative analysis of the mitochondrial DNA from present day humans (52 sequences), ancient Homo sapiens, or archaic AMH (41 sequences) and Neandertals (9 sequences) were aligned to identify single nucleotide variants. The 52 sequences of present day human mtDNA, representing all major mitochondrial haplogroups (Supplementary Table S1), were selected from the PhyloTREE database (Oven and Kayser, 2009) and downloaded from GenBank. Paleogenomes mtDNA sequences were downloaded from GenBank for 42 archaic $\mathrm{AMH}$ (H. sapiens) and 9 Neandertal mtDNA (Table 1). Neandertal signatures, or NSNVs, were determined as positions that were identical between present day sequences and Neandertal sequences at the exclusion of archaic AMH.

\section{Sequence assembly and alignments}

The Ust-Ishim sequence was assembled using reads downloaded from Study PRJEB6622 at the European Nucleotide Archive (EMBL-EBI) and assembled using the CLC Genomics Workbench 7 program (https://www.qiagenbioinformatics.com). To maintain the reference numbering, sequences were aligned to the revised Cambridge Reference Sequence (rRCS; GenBank accession number NC012920) (Andrews et al., 1999), totalizing 103 sequences using the map to reference option implemented in Geneious 10 program (Kearse et al., 2012). Variants were called using Geneious 10 program. A total of 918 polymorphic positions were found. Neandertals, ancient and modern humans were screened for disease associations at MitoMap (http://www.mitomap.org/MITOMAP) (Lott et al., 2013).

\section{Phylogenetic inference}

Position specific similarities between modern haplogroups and Neandertals were depicted by cladograms for each of the single 66 variant positions present only in Neandertals and modern humans and excluding archaic $\mathrm{AMH}$, were generated using parsimony heuristic search implemented in PAUP v4.1a152 with the default parameters (Swofford, 2001). 
bioRxiv preprint doi: https://doi.org/10.1101/190363; this version posted February 6, 2019. The copyright holder for this preprint (which was not certified by peer review) is the author/funder. All rights reserved. No reuse allowed without permission.

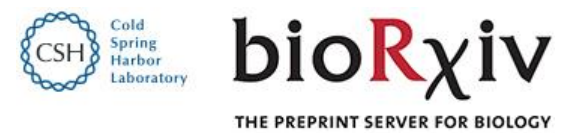

Proximity of mitochondrial haplogoups in Ancient $H$. sapiens and Neandertals were inferred using Haplogrep 2.1.0 (Weissensteiner et al., 2016). All 66 cladograms, corresponding to each N-SNV, are available upon request.

\section{Recombination analysis}

Potential recombination between Neandertals and ancient $H$. sapiens sequences was inferred by a phylogenetic based method implemented by manual bootscan in the Recombination Detection Program (RDP) v.4.87. Parameters for bootscan analysis were: window size $=200$; step size $=20$; bootstrap replicates $=1,000$; cutoff percentage $=70$; use neighbor joining trees; calculate binomial p-value; model option = Kimura 1980 (Kimura, 1980). For each analysis, a single alignment was created which included the modern haplogroup, all 9 Neandertal and all 6 Ancient $H$. sapiens sequences. When rCRS was used as query, two sets of possible parental sequences were selected: either Neandertals Mezmaiskaya and Altai and ancient $H$. sapiens Fumane and Ust Ishim or only Neandertals Feldhofer1, Mezmaiskaya and Vindija 33.16. For haplogroups LOd1a and L3d3b possible parental sequences were Neandertals Feldhofer1, Mezmaiskaya and Vindija 33.16 and Ancient H. sapiens Kostenki 14, Fumane, Doni Vestonice 14 and Tianyuan. For haplogroups M29a and R0a possible parental sequences were Neandertals Mezmaiskaya and Altai and Ancient H. sapiens Kostenki 14 and Doni Vestonice 14. For haplogroup N1b1a3 possible parental sequences were Neandertals Feldhofer1 and Vindija 33.16 and Ancient H. sapiens Kostenki 14 and Doni Vestonice 14.

\section{Statistical analysis}

For variants (SNVs) calling three different datasets were used: (1) the whole mitogenome from the 102 sequences alignment; (2) the 128 to 315bp fragment and (3) the 6,950 to 7,660 fragment of the same alignment. All fasta alignments were processed using the MSA2VCF software to generate the VCF files (Lindenbaum, 2015). The options used on msa2vcf were: -haploid --output. To convert the VCF files to Plink format we used the vcftools package (Danecek et al., 2011). Whole mitogenome alignment with 103 sequences had 785 SNPs (positions containing gaps in at least one sequence were excluded from the analysis). Both $128-315$ and 6,950-7,660 fragments had 24 SNPs.

Principal component analysis was performed using the PLINK software v1.90b4 (Chang et al., 2015; Purcell et al., 2007). PCA figure plotting was made using Genesis PCA and admixture plot viewer (http://www.bioinf.wits.ac.za/software/genesis/). The first two principal components were chosen for the Neandertal - H. sapiens comparison.

\section{References}

Alvares, R. D. A., Tulumello, D. V., Macdonald, P. M., Deber, C. M., and Prosser, R. S. (2013). Effects of a polar amino acid substitution on helix formation and aggregate size along the detergent-induced peptide folding pathway. Biochim. Biophys. Acta BBA - Biomembr. 1828, 373-381. doi:10.1016/j.bbamem.2012.09.024.

Andrews, R. M., Kubacka, I., Chinnery, P. F., Lightowlers, R. N., Turnbull, D. M., and Howell, N. (1999). Reanalysis and revision of the Cambridge reference sequence for human mitochondrial DNA. Nat. Genet. 23, 147. doi:10.1038/13779. 
bioRxiv preprint doi: https://doi.org/10.1101/190363; this version posted February 6, 2019. The copyright holder for this preprint (which was not certified by peer review) is the author/funder. All rights reserved. No reuse allowed without permission.

\section{이를 bioRxiv}

Bergsten, J. (2005). A review of long-branch attraction. Cladistics 21, 163-193. doi:10.1111/j.10960031.2005.00059.x.

Briggs, A. W., Good, J. M., Green, R. E., Krause, J., Maricic, T., Stenzel, U., et al. (2009). Targeted Retrieval and Analysis of Five Neandertal mtDNA Genomes. Science 325, 318-321. doi:10.1126/science.1174462.

Chang, C. C., Chow, C. C., Tellier, L. C., Vattikuti, S., Purcell, S. M., and Lee, J. J. (2015). Second-generation PLINK: rising to the challenge of larger and richer datasets. GigaScience 4, 7. doi:10.1186/s13742-0150047-8.

Danecek, P., Auton, A., Abecasis, G., Albers, C. A., Banks, E., DePristo, M. A., et al. (2011). The variant call format and VCFtools. Bioinformatics 27, 2156-2158. doi:10.1093/bioinformatics/btr330.

D’Aurelio, M., Gajewski, C. D., Lin, M. T., Mauck, W. M., Shao, L. Z., Lenaz, G., et al. (2004). Heterologous mitochondrial DNA recombination in human cells. Hum. Mol. Genet. 13, 3171-3179. doi: $10.1093 / \mathrm{hmg} / \mathrm{ddh} 326$.

Dokianakis, E., and Ladoukakis, E. D. (2014). Different degree of paternal mtDNA leakage between male and female progeny in interspecific Drosophila crosses. Ecol. Evol. 4, 2633-2641. doi:10.1002/ece3.1069.

Felsenstein, J. (1974). The evolutionary advantage of recombination. Genetics 78, 737-756.

Fitzpatrick, E., Bourke, B., Drumm, B., and Rowland, M. (2008). The incidence of cyclic vomiting syndrome in children: population-based study. Am. J. Gastroenterol. 103, 991-995; quiz 996. doi:10.1111/j.15720241.2007.01668.x.

Formicola, V., Pontrandolfi, A., and Svoboda, J. (2001). The Upper Paleolithic triple burial of Dolní Věstonice: Pathology and funerary behavior. Am. J. Phys. Anthropol. 115, 372-379. doi:10.1002/ajpa.1093.

Fu, Q., Li, H., Moorjani, P., Jay, F., Slepchenko, S. M., Bondarev, A. A., et al. (2014). Genome sequence of a 45,000-year-old modern human from western Siberia. Nature 514, 445-449. doi:10.1038/nature13810.

Fu, Q., Mittnik, A., Johnson, P. L. F., Bos, K., Lari, M., Bollongino, R., et al. (2013). A Revised Timescale for Human Evolution Based on Ancient Mitochondrial Genomes. Curr. Biol. 23, 553-559. doi:10.1016/j.cub.2013.02.044.

Gansauge, M.-T., and Meyer, M. (2014). Selective enrichment of damaged DNA molecules for ancient genome sequencing. Genome Res., gr.174201.114. doi:10.1101/gr.174201.114.

GBD Compare | IHME Viz Hub Available at: http://vizhub.healthdata.org/gbd-compare [Accessed January 31, 2019].

Gibbons, A. (2010). Close Encounters of the Prehistoric Kind. Science 328, 680-684. doi:10.1126/science.328.5979.680.

Green, R. E., Krause, J., Briggs, A. W., Maricic, T., Stenzel, U., Kircher, M., et al. (2010). A Draft Sequence of the Neandertal Genome. Science 328, 710-722. doi:10.1126/science.1188021.

Green, R. E., Malaspinas, A.-S., Krause, J., Briggs, A. W., Johnson, P. L. F., Uhler, C., et al. (2008). A Complete Neandertal Mitochondrial Genome Sequence Determined by High-Throughput Sequencing. Cell 134, 416426. doi:10.1016/j.cell.2008.06.021.

Hanif, F., Muzaffar, K., Perveen, K., Malhi, S. M., and Simjee, S. U. (2017). Glioblastoma Multiforme: A Review of its Epidemiology and Pathogenesis through Clinical Presentation and Treatment. Asian Pac. J. Cancer 
bioRxiv preprint doi: https://doi.org/10.1101/190363; this version posted February 6, 2019. The copyright holder for this preprint (which was not certified by peer review) is the author/funder. All rights reserved. No reuse allowed without permission.

Prev. APJCP 18, 3-9. doi:10.22034/APJCP.2017.18.1.3.

\section{bioR $\chi i v$}

THE PREPRINT SERVER FOR BIOLOGY

Henn, B. M., Botigué, L. R., Gravel, S., Wang, W., Brisbin, A., Byrnes, J. K., et al. (2012). Genomic Ancestry of North Africans Supports Back-to-Africa Migrations. PLOS Genet. 8, e1002397. doi:10.1371/journal.pgen.1002397.

Hervella, M., Svensson, E. M., Alberdi, A., Günther, T., Izagirre, N., Munters, A. R., et al. (2016). The mitogenome of a 35,000-year-old Homo sapiens from Europe supports a Palaeolithic back-migration to Africa. Sci. Rep. 6, 25501. doi:10.1038/srep25501.

Higham, T., Douka, K., Wood, R., Ramsey, C. B., Brock, F., Basell, L., et al. (2014). The timing and spatiotemporal patterning of Neanderthal disappearance. Nature 512, 306-309. doi:10.1038/nature13621.

Hill, G. E., and Johnson, J. D. (2013). The mitonuclear compatibility hypothesis of sexual selection. Proc R Soc B 280, 20131314. doi:10.1098/rspb.2013.1314.

Horai, S., Hayasaka, K., Kondo, R., Tsugane, K., and Takahata, N. (1995). Recent African origin of modern humans revealed by complete sequences of hominoid mitochondrial DNAs. Proc. Natl. Acad. Sci. U. S. A. $92,532-536$.

Kearse, M., Moir, R., Wilson, A., Stones-Havas, S., Cheung, M., Sturrock, S., et al. (2012). Geneious Basic: An integrated and extendable desktop software platform for the organization and analysis of sequence data. Bioinformatics 28, 1647-1649. doi:10.1093/bioinformatics/bts199.

Kimura, M. (1980). A simple method for estimating evolutionary rates of base substitutions through comparative studies of nucleotide sequences. J. Mol. Evol. 16, 111-120.

Ko, K. H. (2016). Hominin interbreeding and the evolution of human variation. J. Biol. Res.-Thessalon. $23,17$. doi:10.1186/s40709-016-0054-7.

Kraytsberg, Y., Schwartz, M., Brown, T. A., Ebralidse, K., Kunz, W. S., Clayton, D. A., et al. (2004). Recombination of Human Mitochondrial DNA. Science 304, 981-981. doi:10.1126/science.1096342.

Lancet, T. (2016). Hearing loss: an important global health concern. The Lancet 387, 2351. doi:10.1016/S01406736(16)30777-2.

Lin, F.-H., Lin, R., Wisniewski, H. M., Hwang, Y.-W., Grundke-Iqbal, I., Healy-Louie, G., et al. (1992). Detection of point mutations in codon 331 of mitochondrial NADH dehydrogenase subunit 2 in alzheimer's brains. Biochem. Biophys. Res. Commun. 182, 238-246. doi:10.1016/S0006-291X(05)80136-6.

Lindenbaum, P. (2015). JVarkit: java-based utilities for Bioinformatics. doi:10.6084/m9.figshare.1425030.v1.

Lott, M. T., Leipzig, J. N., Derbeneva, O., Xie, H. M., Chalkia, D., Sarmady, M., et al. (2013). mtDNA Variation and Analysis Using Mitomap and Mitomaster. Curr. Protoc. Bioinforma. 44, 1.23.1-1.23.26. doi:10.1002/0471250953.bi0123s44.

Mita, S., Rizzuto, R., Moraes, C. T., Shanske, S., Arnaudo, E., Fabrizi, G. M., et al. (1990). Recombination via flanking direct repeats is a major cause of large-scale deletions of human mitochondrial DNA. Nucleic Acids Res. 18, 561-567.

Neiman, M., and Taylor, D. R. (2009). The causes of mutation accumulation in mitochondrial genomes. Proc. $R$. Soc. B Biol. Sci. 276, 1201-1209. doi:10.1098/rspb.2008.1758.

Oven, M. van, and Kayser, M. (2009). Updated comprehensive phylogenetic tree of global human mitochondrial 
bioRxiv preprint doi: https://doi.org/10.1101/190363; this version posted February 6, 2019. The copyright holder for this preprint (which was not certified by peer review) is the author/funder. All rights reserved. No reuse allowed without permission.

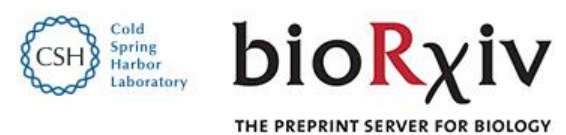

DNA variation. Hum. Mutat. 30, E386-E394. doi:10.1002/humu.20921.

Petruzzella, V., Chen, X., and Schon, E. A. (1992). Is a point mutation in the mitochondrial ND2 gene associated with alzheimer's disease? Biochem. Biophys. Res. Commun. 186, 491-497. doi:10.1016/S0006$291 \mathrm{X}(05) 80834-4$.

Podoly, E., Hanin, G., and Soreq, H. (2010). Alanine-to-threonine substitutions and amyloid diseases: Butyrylcholinesterase as a case study. Chem. Biol. Interact. 187, 64-71. doi:10.1016/j.cbi.2010.01.003.

Posada, D., and Crandall, K. A. (2001). Evaluation of methods for detecting recombination from DNA sequences: Computer simulations. Proc. Natl. Acad. Sci. 98, 13757-13762. doi:10.1073/pnas.241370698.

Posth, C., Renaud, G., Mittnik, A., Drucker, D. G., Rougier, H., Cupillard, C., et al. (2016). Pleistocene Mitochondrial Genomes Suggest a Single Major Dispersal of Non-Africans and a Late Glacial Population Turnover in Europe. Curr. Biol. 26, 827-833. doi:10.1016/j.cub.2016.01.037.

Prüfer, K., Racimo, F., Patterson, N., Jay, F., Sankararaman, S., Sawyer, S., et al. (2014). The complete genome sequence of a Neanderthal from the Altai Mountains. Nature 505, 43-49. doi:10.1038/nature12886.

Purcell, S., Neale, B., Todd-Brown, K., Thomas, L., Ferreira, M. A. R., Bender, D., et al. (2007). PLINK: A Tool Set for Whole-Genome Association and Population-Based Linkage Analyses. Am. J. Hum. Genet. 81, 559575.

Racimo, F., Marnetto, D., and Huerta-Sánchez, E. (2017). Signatures of Archaic Adaptive Introgression in PresentDay Human Populations. Mol. Biol. Evol. 34, 296-317. doi:10.1093/molbev/msw216.

Rieux, A., Eriksson, A., Li, M., Sobkowiak, B., Weinert, L. A., Warmuth, V., et al. (2014). Improved Calibration of the Human Mitochondrial Clock Using Ancient Genomes. Mol. Biol. Evol. 31, 2780-2792. doi:10.1093/molbev/msu222.

Schnopp, N. M., Kösel, S., Egensperger, R., and Graeber, M. B. (1996). Regional heterogeneity of mtDNA heteroplasmy in parkinsonian brain. Clin. Neuropathol. 15, 348-352.

Schwartz, M., and Vissing, J. (2002). Paternal Inheritance of Mitochondrial DNA. N. Engl. J. Med. 347, 576-580. doi:10.1056/NEJMoa020350.

Serre, D., Langaney, A., Chech, M., Teschler-Nicola, M., Paunovic, M., Mennecier, P., et al. (2004). No Evidence of Neandertal mtDNA Contribution to Early Modern Humans. PLOS Biol. 2, e57. doi:10.1371/journal.pbio.0020057.

Simonti, C. N., Vernot, B., Bastarache, L., Bottinger, E., Carrell, D. S., Chisholm, R. L., et al. (2016). The phenotypic legacy of admixture between modern humans and Neandertals. Science 351, 737-741. doi:10.1126/science.aad2149.

Steiper, M. E., and Young, N. M. (2006). Primate molecular divergence dates. Mol. Phylogenet. Evol. 41, 384-394. doi:10.1016/j.ympev.2006.05.021.

Swofford, D. L. (2001). PAUP*: Phylogenetic Analysis Using Parsimony (and other methods) 4.0.b5.

Thomas, M. G., Miller, K. W. P., and Mascie-Taylor, C. G. N. (1998). Mitochondrial DNA and IQ in Europe. Intelligence 26, 167-173. doi:10.1016/S0160-2896(99)80060-9.

Volkenstein, M. V. (1965). Coding of Polar and Non-polar Amino-acids. Nature 207, 294-295. doi:10.1038/207294a0. 
bioRxiv preprint doi: https://doi.org/10.1101/190363; this version posted February 6, 2019. The copyright holder for this preprint (which was not certified by peer review) is the author/funder. All rights reserved. No reuse allowed without permission.

\section{Acknowledgments}

The authors thank Prof. Dajiang Liu (Dept. Public Health Sciences, Penn State College of Medicine) and Prof. Rongling Wu (Center for Statistical Genetics, Penn State University) for critical reading of the manuscript. This work was supported by grants to M.R.S.B. from FAPESP, Brazil (2013/07838-0 and 2014/25602-6) and CNPq, Brazil (303905/2013- 1). R.C.F received a CNPq postdoctoral fellowship (206445/2014-8) and C.R.R. a CAPES (Brazil) MSc fellowship. Author contributions: R.C.F. and C.R.R. planned and performed analyses. M.R.S.B. performed preliminary analysis and wrote the manuscript. R.C.F., C.R.R., J.R.B and M.R.S.B. discussed data and analyses and edited the manuscript. Competing interests: The authors declare no competing interests. Data and materials availability: All data and files of analyses here presented are available upon request to the corresponding author. 
bioRxiv preprint doi: https://doi.org/10.1101/190363; this version posted February 6, 2019. The copyright holder for this preprint (which was not certified by peer review) is the author/funder. All rights reserved. No reuse allowed without permission.

\section{소를 bioR Xiv \\ THE PREPRINT SERVER FOR BIOLOGY}

\section{Table 1. Archaic AMH and Neandertal mitogenomes used in this study. Haplogroup inference quality** as calculated by Haplogrep 2 (Weissensteiner et al., 2016).}

\begin{tabular}{|c|c|c|c|c|c|c|}
\hline Archaic AMH & Haplogroup & Quality** (\%) & Age (years) & Location & Reference & GenBank/ENA* \\
\hline Berry Au Bac 1 & U5b1a & 98.78 & $7,160-7,319$ & France & (Posth et al., 2016) & KU534977 \\
\hline Bockstein & U5b1d1 & 98.72 & $8,016-8,329$ & Germany & (Posth et al., 2016) & KU534973 \\
\hline Cuiry Les Chaudardes 1 & U5b1b & 97.01 & $8,050-8,360$ & France & (Posth et al., 2016) & KU534975 \\
\hline Ofnet & U5b1d1 & 98.72 & $8,159-8,424$ & Germany & (Posth et al., 2016) & KU534974 \\
\hline Felsdach & $\mathrm{U} 5 \mathrm{a} 2 \mathrm{c}$ & 97.43 & $8,380-8,980$ & Germany & (Posth et al., 2016) & KU534954 \\
\hline Hohlenstein Stadel & $\mathrm{U} 5 \mathrm{~b} 2 \mathrm{c} 1$ & 94.77 & $8,446-8,809$ & Germany & (Posth et al., 2016) & KU534979 \\
\hline Falkenstein & $\mathrm{U} 5 \mathrm{~b} 2 \mathrm{a}$ & 92.19 & $8,993-9,409$ & Germany & (Posth et al., 2016) & KU534980 \\
\hline Mareuil Les Meaux 1 & $\mathrm{U} 5 \mathrm{a} 2+16362$ & 100 & $9,080-9,500$ & France & (Posth et al., 2016) & KU534959 \\
\hline Les Closeaux 3 & $\mathrm{U} 5 \mathrm{a} 2$ & 98.27 & $9,580-10,230$ & France & (Posth et al., 2016) & KU534958 \\
\hline Ranchot 88 & U5b1 & 95.95 & $9,933-10,235$ & France & (Posth et al., 2016) & KU534978 \\
\hline Iboussieres 31-2 & U5b1+16189 & 99.01 & 10,140 & France & (Posth et al., 2016) & KU534976 \\
\hline Iboussieres $25-1$ & $\mathrm{U} 5 \mathrm{~b} 2 \mathrm{a}$ & 93.92 & 10,140 & France & (Posth et al., 2016) & KU534981 \\
\hline Iboussieres 39 & $\mathrm{U} 5 \mathrm{~b} 2 \mathrm{~b}$ & 92.40 & $11,600-12,040$ & France & (Posth et al., 2016) & KU534972 \\
\hline Hohle Fels 10 & U8a & 96.92 & 12,700 & Germany & (Posth et al., 2016) & KU534961 \\
\hline Rochedane & $\mathrm{U} 5 \mathrm{~b} 2 \mathrm{~b}$ & 97.01 & $12,830-13,090$ & France & (Posth et al., 2016) & KU534971 \\
\hline Burkhardtshohle & U8a & 96.92 & $14,150-15,080$ & Germany & (Posth et al., 2016) & KU534960 \\
\hline Hohle Fels 79 & U8a & 96.92 & $14,270-15,070$ & Germany & (Posth et al., 2016) & KU534962 \\
\hline Brillenhohle & U8a & 97.66 & $14,400-15,120$ & Germany & (Posth et al., 2016) & KU534947 \\
\hline Oberkassel 998 & $\mathrm{U} 5 \mathrm{~b} 1+$ & 99.45 & 14,000 & Germany & (Hervella et al., 2016) & KC521457 \\
\hline Goyet Q-2 & U8a & 96.92 & $14,780-15,230$ & Belgium & (Posth et al., 2016) & KU534963 \\
\hline Rigney 1 & U2'3'4'7'8'9 & 87.68 & $15,240-15,690$ & France & (Posth et al., 2016) & KU534957 \\
\hline Hohle Fels 49 & U8a & 96.92 & $15,568-16,250$ & Germany & (Posth et al., 2016) & KU534964 \\
\hline Paglicci 71 & $\mathrm{U} 5 \mathrm{~b} 2 \mathrm{~b}$ & 97.97 & $18,197-18,973$ & Italy & (Posth et al., 2016) & KU534950 \\
\hline Dolni Vestonice 43 & U5 & 97.44 & 25,000 & Czech Rep. & (Posth et al., 2016) & KU534970 \\
\hline Goyet Q56-16 & U2 & 91.40 & $26,040-26,600$ & Belgium & (Posth et al., 2016) & KU534965 \\
\hline Goyet $2878-21$ & U5 & 92.05 & $26,269-27,055$ & Belgium & (Posth et al., 2016) & KU534955 \\
\hline Goyet Q376-19 & $\mathrm{U} 2$ & 89.43 & $27,310-27,720$ & Belgium & (Posth et al., 2016) & KU534967 \\
\hline Goyet Q55-2 & $\mathrm{U} 2$ & 85.86 & $27,310-27,730$ & Belgium & (Posth et al., 2016) & KU534948 \\
\hline La Rochette & $\mathrm{M}$ & 92.38 & $27,400-27,784$ & France & (Posth et al., 2016) & KU534951 \\
\hline Goyet Q53-1 & $\mathrm{U} 2$ & 93.23 & $27,720-28,230$ & Belgium & (Posth et al., 2016) & KU534966 \\
\hline Paglicci 108 & U2'3'4'7'8'9 & 92.40 & $27,831-28,961$ & Italy & (Posth et al., 2016) & KU534968 \\
\hline Paglicci 133 & $\mathrm{U} 8 \mathrm{c}$ & 99.41 & $28,000-29,000$ & Italy & (Posth et al., 2016) & KU534956 \\
\hline Dolni Vestonice 16 & U5 & 97.94 & $29,386-30,567$ & Czech Rep. & (Posth et al., 2016) & KU534949 \\
\hline Doni Vestonice 14 & U5 & 100 & 31,000 & Czech Rep. & (Formicola et al., 2001) & KC521458 \\
\hline Cioclovina 1 & $\mathrm{U}$ & 96.72 & $32,519-33,905$ & Romania & (Posth et al., 2016) & KU534969 \\
\hline Goyet Q376-3 & M & 88.67 & $33,140-33940$ & Belgium & (Posth et al., 2016) & KU534953 \\
\hline Goyet Q116-1 & M & 93.64 & $34,430-35,160$ & Belgium & (Posth et al., 2016) & KU534952 \\
\hline Kostenki 14 & $\mathrm{U} 2$ & 92.69 & $36-39,000$ & Russia & (Hervella et al., 2016) & FN600416* \\
\hline Fumane 2 & $\mathrm{R}$ & 94.43 & $39-41,000$ & Italy & (Hervella et al., 2016) & KP718913 \\
\hline Tianyuan & $\mathrm{B} 4{ }^{\prime} 5$ & 91.17 & 40,000 & China & (Fu et al., 2013) & KC417443 \\
\hline Ust-Ishim & $\mathrm{R}$ & 87.89 & 45,000 & West Siberia & (Hervella et al., 2016) & PRJEB6622* \\
\hline \multicolumn{7}{|l|}{ Neandertals } \\
\hline Vindija 33.16 & H1e & 52.74 & 38,000 & Croatia & (Green et al., 2008) & AM948965 \\
\hline Vindija 33.17 & H1e & 52.75 & Not dated & Croatia & $\begin{array}{l}\text { (Gansauge and Meyer, } \\
\text { 2014) }\end{array}$ & KJ533544 \\
\hline Vindija 33.19 & $\mathrm{H} 1 \mathrm{e}$ & 52.74 & Not dated & Croatia & $\begin{array}{l}\text { (Gansauge and Meyer, } \\
\text { 2014) }\end{array}$ & KJ533545 \\
\hline Vindija 33.25 & H1as & 52.84 & Not dated & Croatia & (Briggs et al., 2009) & FM865410 \\
\hline El Sidron 1253 & H1e & 52.81 & 39,000 & Spain & $\begin{array}{l}\text { (Briggs et al., 2009; } \\
\text { Hervella et al., 2016) }\end{array}$ & FM865409 \\
\hline Feldhofer 1 & $\mathrm{H} 1 \mathrm{as}$ & 52.84 & 40,000 & Germany & (Briggs et al., 2009) & FM865407 \\
\hline Feldhofer 2 & H1e & 52.81 & 40,000 & Germany & (Briggs et al., 2009) & FM865408 \\
\hline Altai Neandertal & L1'2'3'4'5'6 & 55.96 & 50,000 & Siberia & (Prüfer et al., 2014) & KC879692 \\
\hline Mezmaskaya 1 & L1'2'3'4'5'6 & 52.12 & 65,000 & Russia & (Briggs et al., 2009) & FM865411 \\
\hline
\end{tabular}


bioRxiv preprint doi: https://doi.org/10.1101/190363; this version posted February 6, 2019. The copyright holder for this preprint (which was not certified by peer review) is the author/funder. All rights reserved. No reuse allowed without permission.

Table 2. Disease associated Neandertal SNVs. Associations as compiled and summarized in MITOMAP (Lott et al., 2013).

\begin{tabular}{|c|c|c|c|c|c|c|c|}
\hline Position & 195 & 3,010 & 5,460 & 5,821 & 16,093 & 16,183 & 16,519 \\
\hline Region / gene & D-loop & 16S rRNA & ND2 & tRNA-Cys & D-loop & D-loop & D-loop \\
\hline dbSNP rs & rs2857291 & rs3928306 & rs3021088 & rs56133209 & rs2853511 & rs28671493 & rs3937033 \\
\hline DNA change & $\mathrm{T}>\mathrm{C}$ & $\mathrm{G}>\mathrm{A}$ & $\mathrm{G}>\mathrm{A}$ & $\mathrm{G}>\mathrm{A}$ & $\mathrm{T}>\mathrm{C}$ & $\mathrm{A}>\mathrm{C}$ & $\mathrm{T}>\mathrm{C}$ \\
\hline Type & Transition & Transition & Transition & Transition & Transition & Transversion & Transition \\
\hline Codon position & & - & 1 & - & - & - & - \\
\hline Codon effect & - & - & Non Syn. & - & - & - & - \\
\hline Codon change & - & - & $\mathrm{GCC}>\mathrm{ACC}$ & - & - & - & - \\
\hline Protein change & - & - & Ala $>$ Thr & - & - & - & - \\
\hline $\begin{array}{l}\text { Disease } \\
\text { associations }\end{array}$ & $\begin{array}{l}\text { Bipolar } \\
\text { disorder / } \\
\text { melanoma } \\
\text { patients }\end{array}$ & $\begin{array}{l}\text { Cyclic } \\
\text { Vomiting } \\
\text { Syndrome with } \\
\text { Migraine }\end{array}$ & $\begin{array}{l}\text { Alzheimer`s } \\
\text { disease / } \\
\text { Parkinson`s } \\
\text { disease }\end{array}$ & $\begin{array}{l}\text { Deafness } \\
\text { helper } \\
\text { mutation }\end{array}$ & $\begin{array}{l}\text { Cyclic } \\
\text { Vomiting } \\
\text { Syndrome }\end{array}$ & $\begin{array}{l}\text { Melanoma } \\
\text { patients }\end{array}$ & $\begin{array}{l}\text { Cyclic Vomiting } \\
\text { Syndrome with } \\
\text { Migraine /metastasis / } \\
\text { glioblastoma, gastric, } \\
\text { lung, ovarian, prostate } \\
\text { tumors }\end{array}$ \\
\hline $\begin{array}{l}\text { Modern } \\
\text { haplogroups }\end{array}$ & $\begin{array}{l}\text { L2a1f, } \\
\text { L4a1, } \\
\text { L5a1a, L6a, } \\
\text { W1, K, } \\
\text { J2a2a, M2b }\end{array}$ & H1a1, J1c, D4 & $\begin{array}{l}\text { L0a1b1, L4a1, } \\
\text { W1, Q1 }\end{array}$ & $\mathrm{C} 7$ & $\begin{array}{l}\text { L4a1, R0a, } \\
\text { K1, H3, T1 } \\
\text { A, C1a }\end{array}$ & $\begin{array}{l}\text { X1a, X3, } \\
\text { U1a1d, B2, } \\
\text { M2b, M29a, O }\end{array}$ & $\begin{array}{l}\text { L1c3a, L2a1f, L6a, } \\
\text { H15, H1a1, H3, I1, K, } \\
\text { K1, K2a2a, R0a1a3, } \\
\text { R1a, U2c, V1a, W1, } \\
\text { X1a, X3, B2, C4, C7, } \\
\text { E1, F1a1, G1a1, M20, } \\
\text { M29a, M2b, M3b, } \\
\text { N1b1a3, N2a, O, P2 }\end{array}$ \\
\hline \multirow[t]{9}{*}{ Neandertal } & Altai & Altai & Altai & Altai & Feldhofer1 & El Sidron 1253 & Altai \\
\hline & & El Sidron 1253 & El Sidron 1253 & El Sidron 1253 & Vin. 33.25 & Feldhofer 1 & El Sidron 1253 \\
\hline & & Feldhofer 1 & Feldhofer 1 & Feldhofer 1 & & Feldhofer 2 & Feldhofer 1 \\
\hline & & Feldhofer 2 & Feldhofer 2 & Feldhofer 2 & & Mezmaiskaya1 & Feldhofer 2 \\
\hline & & Mezmaiskaya1 & Mezmaiskaya1 & Mezmaiskaya1 & & Vindija 33.16 & Mezmaiskaya1 \\
\hline & & Vindija 33.16 & Vindija 33.16 & Vindija 33.16 & & Vindija 33.17 & Vindija 33.16 \\
\hline & & Vindija 33.17 & Vindija 33.17 & Vindija 33.17 & & Vindija 33.19 & Vindija 33.17 \\
\hline & & Vindija 33.19 & Vindija 33.19 & Vindija 33.19 & & Vindija 33.25 & Vindija 33.19 \\
\hline & & Vindija 33.25 & Vindija 33.25 & Vindija 33.25 & & & Vindija 33.25 \\
\hline
\end{tabular}




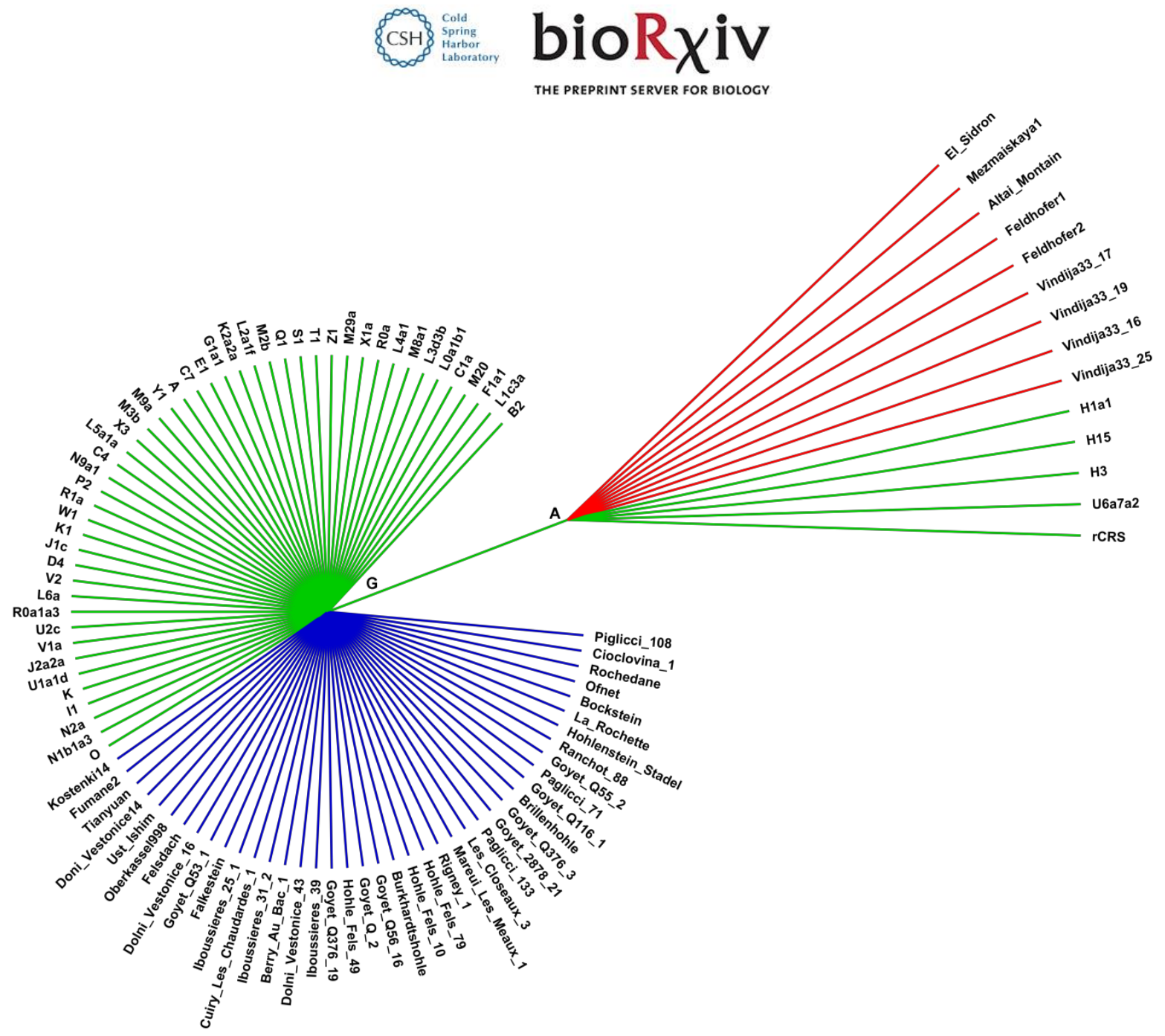

Fig. 1. Cladogram of mitochondrial genome position 2,706. This N-SNV is a G-A transition in the 16S rRNA gene. This genetic signature (Neandertal signature 2706G) is present in all

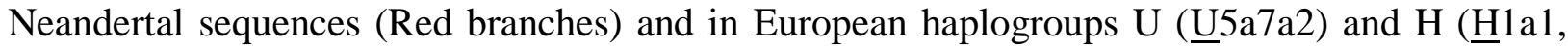
$\underline{\mathrm{H}} 3, \underline{\mathrm{H}} 15)$, including the Revised Cambridge Reference Sequence (rCRS, haplogroup $\underline{\mathrm{H}} 2 \mathrm{a} 2 \mathrm{a} 1)$. The Neandertal signature 2706G is absent in all of the archaic AMH (Anatomically Modern Humans from Europe in temporal overlap with Neandertals - Blue branches) and other modern mitochondrial haplogroups. Position numbering corresponds to rCRS positions. This cladogram is representative of the 66 cladograms generated for each N-SNV giving similar topologies and which are available upon request. 


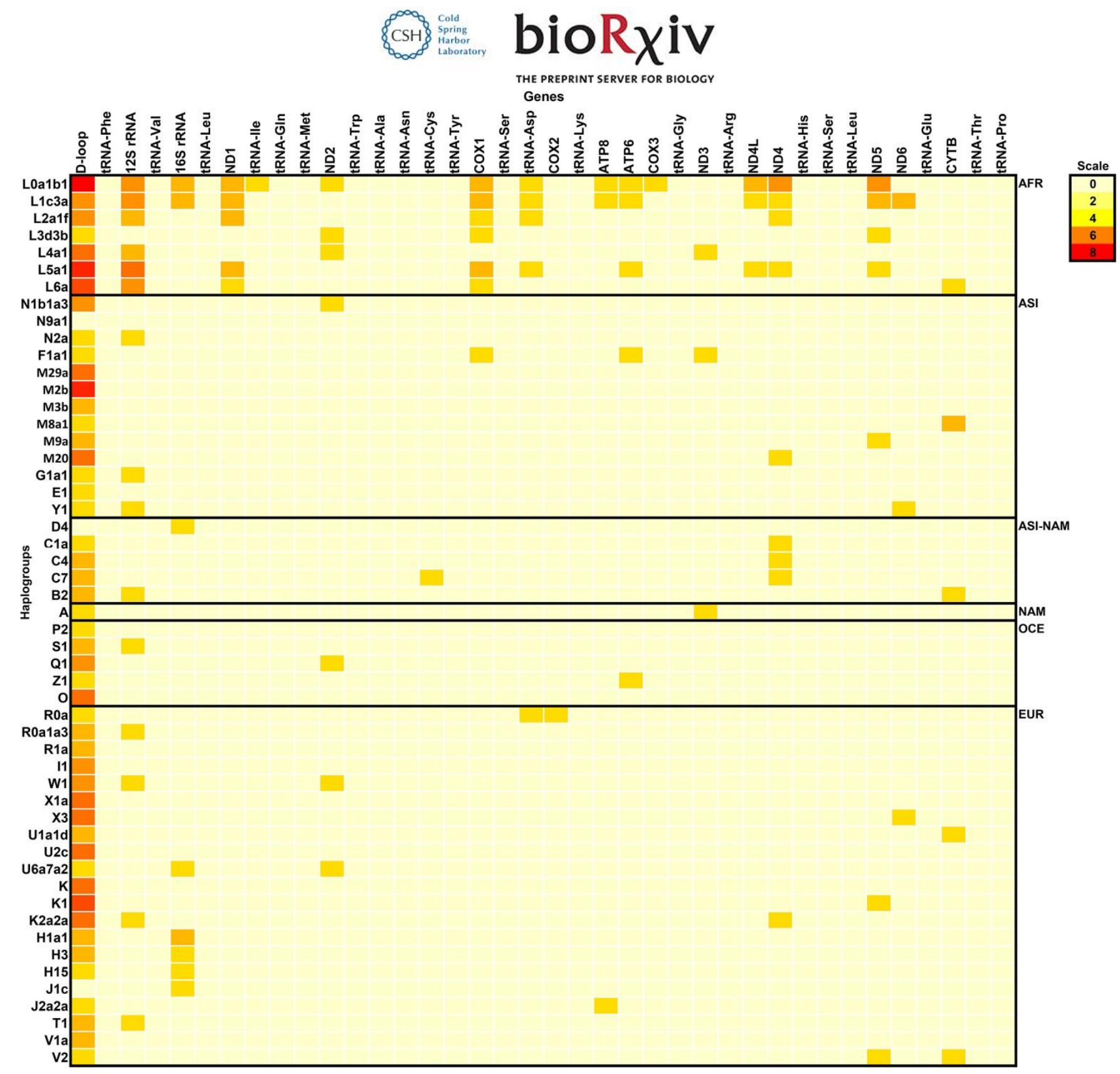

Fig. 2. Heatmap of Neandertal signatures along the mitochondrial genome in different haplogroups. The color scale indicates the number of Neandertal signatures (N-SNVs) present in modern human mitochondrial haplogoups. These signatures are absent in Ancient H. sapiens whose time range overlapped with Neandertals in Europe (from approximately 50,000 to 28,000 years ago, Supplementary Table S2). AFR=African, ASI=Asian, MDE=Middle East, $\mathrm{NAM}=$ Native American, $\mathrm{OCE}=$ Oceania and EUR=European. 


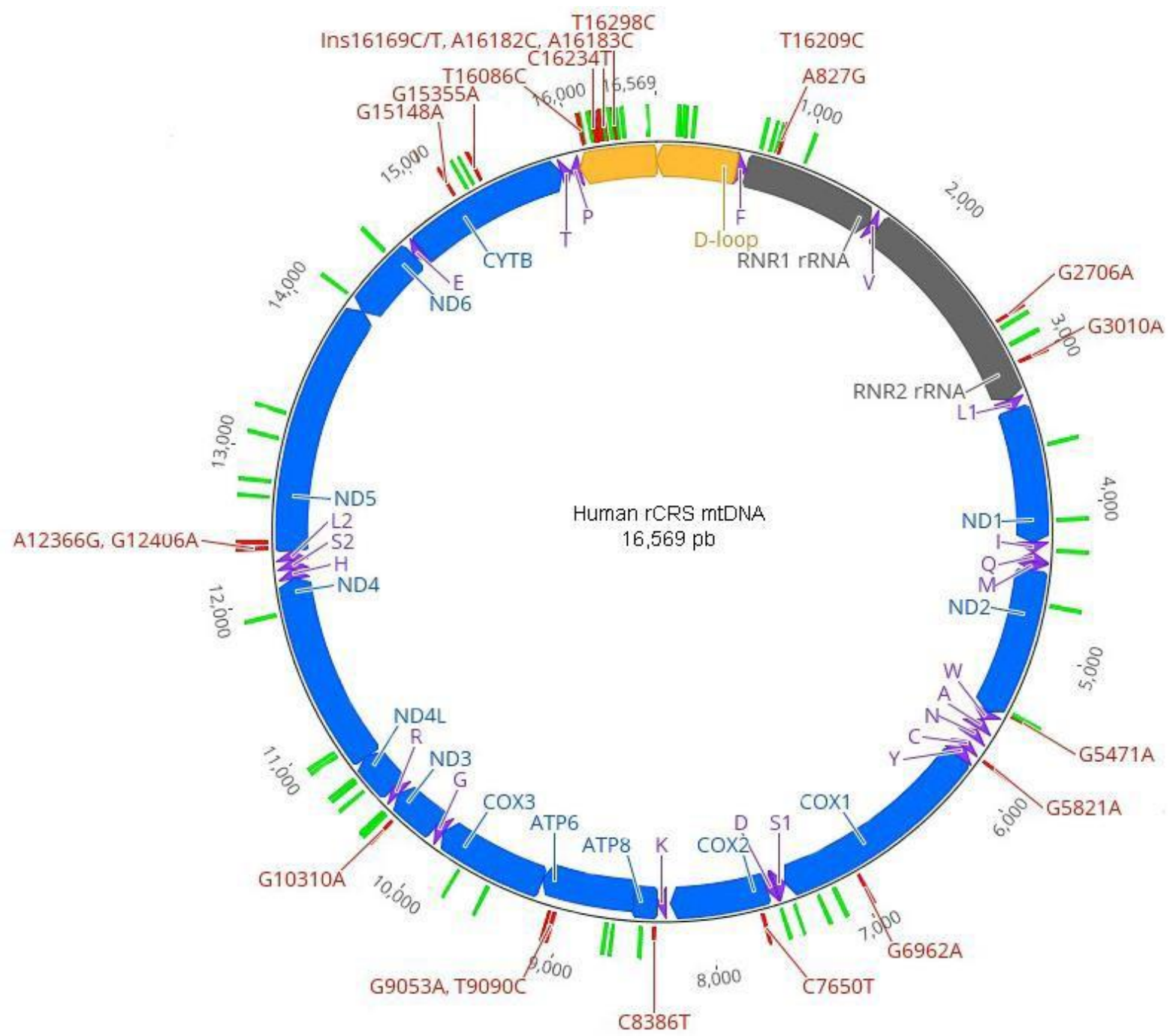

Fig. 3. Position of Neandertal SNVs (N-SNVs) in the mitochondrial genome. Blue bars indicate protein coding genes, gray bars indicate ribosomal RNA genes, purple arrows indicate tRNAs, yellow bars indicate the D-loop, green bars indicate Neandertal SNVs present in African haplogoups and red bars indicate N-SNVs exclusive of Eurasian haplogroups. 


\section{(일 bioRxiv \\ THE PREPRINT SERVER FOR BIOLOGY}

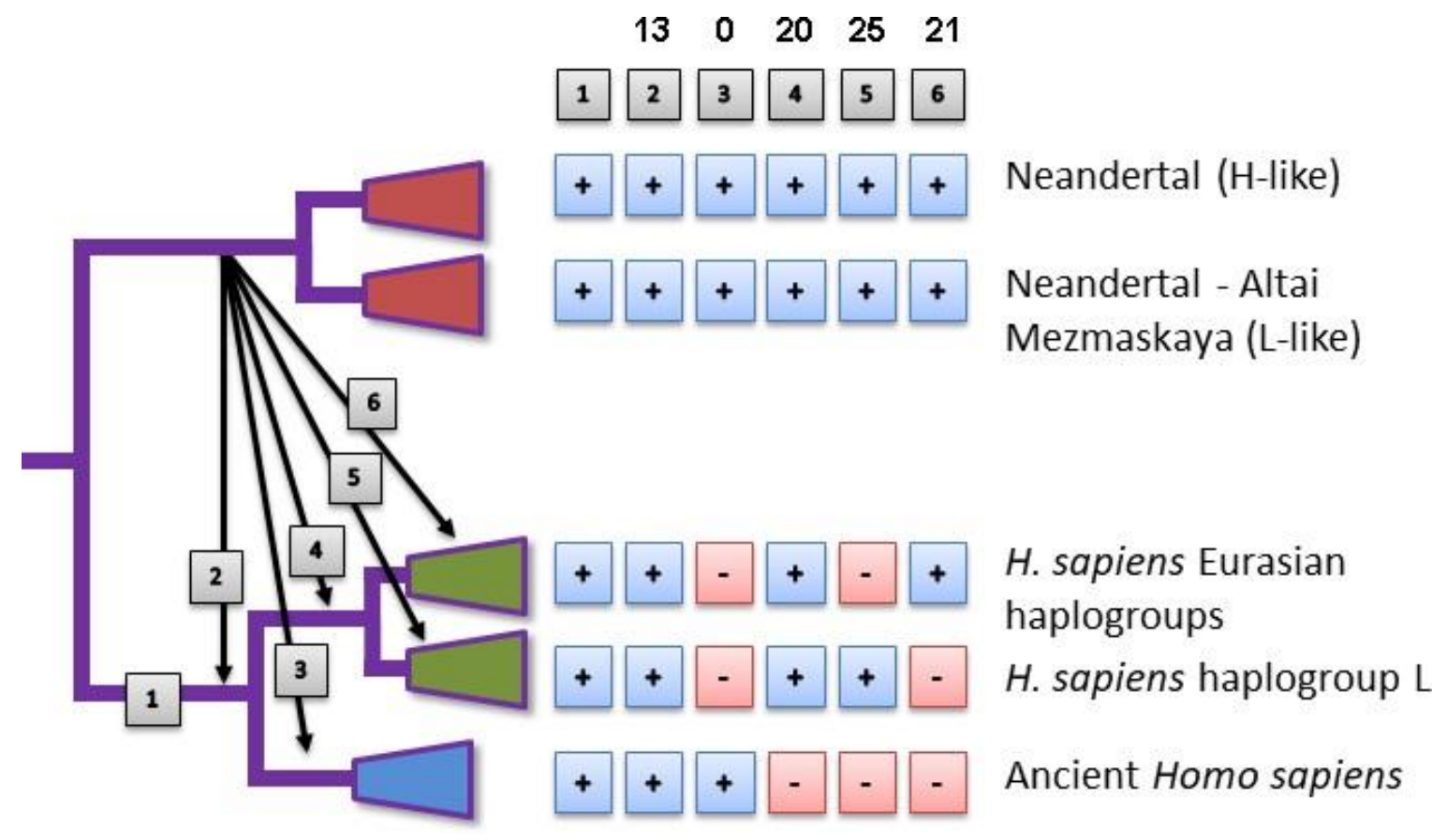

Fig. 4. Possible Neandertal introgression routes and mitogenome SNVs distribuitons. The diagram depicts six possible introgression routes, or intercross events, between Neandertals, archaic $\mathrm{AMH}$ and lineages leading to present day Homo sapiens haplogroups. Hypotheses 1 and 2 would produce plesiomorphic SNVs while hypothesis 3 would exclude present day haplogroups. Hyptheses 4, 5 and 6 would produce patterns in present day haplogroups consistent with more recent crosses between Neandertals and ancestors of present day haplogroups. Numbers above gray boxes indicate the number of specific N-SNVs in that particular clade. Plus (+) and minus (-) signs within blue and red boxes indicate N-SNVs presence or absence in that particular clade. 

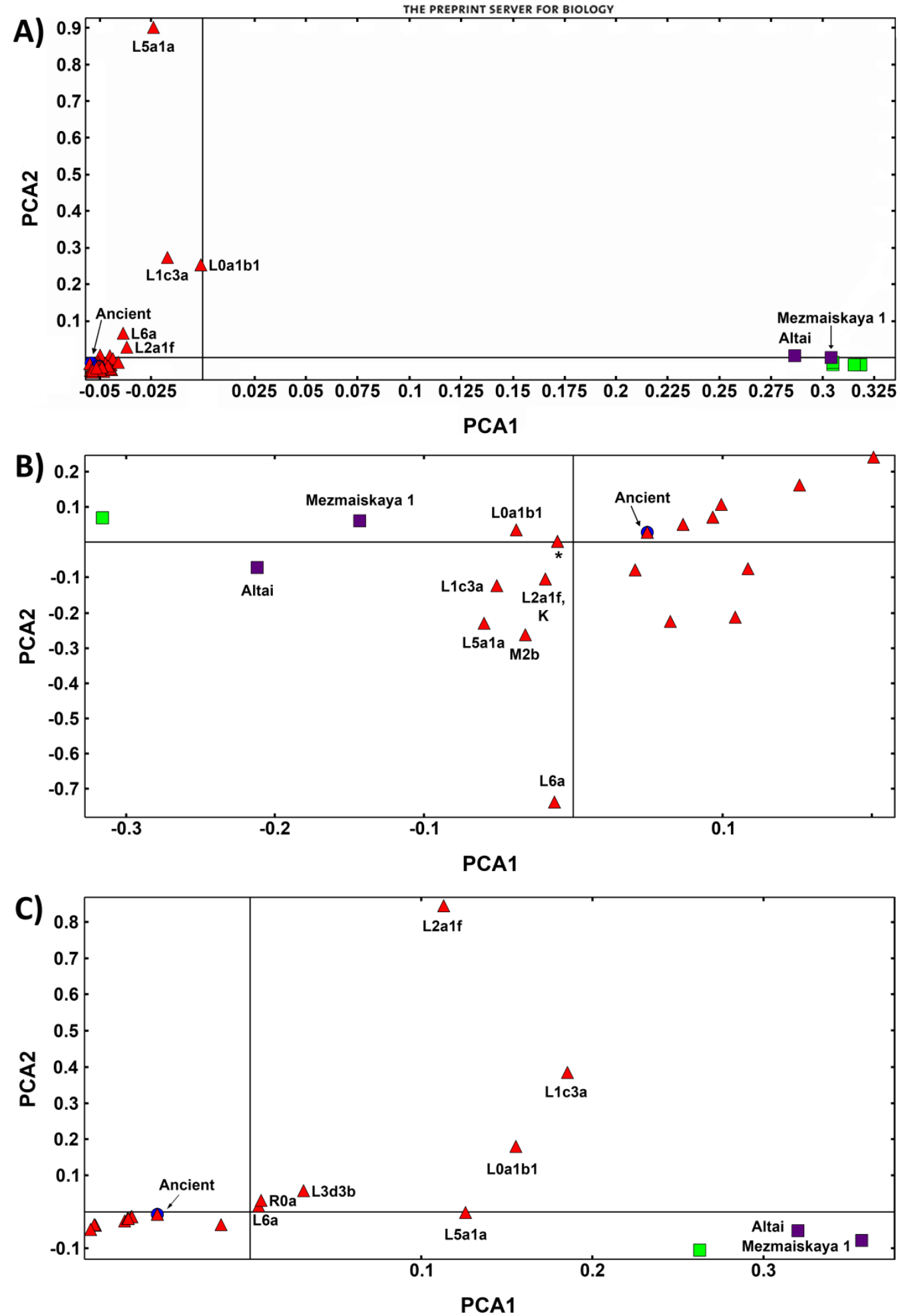

Fig. 5. Principal Component Analysis (PCA) of Human and Neandertal mitochondrial genomes. In (A) PCA results for all 16,569 positions of 103 mitogenomes being 9 Neandertals (green squares for $\mathrm{H}$-like sequences and purple squares for L-like sequences), 42 archaic AMH (blue circles) and 53 modern $H$. sapiens haplogroups (red triangles). X-Axis denotes the value for PC1, while y-Axis denotes values for PC2. Each dot in the figure represents one or more individuals. In (B) PCA results for the segment comprising positions 128 to 315 extracted from the 103 mitogenomes alignment and in (C) PCA results for the segment comprising positions 6,950 to 7,660 extracted from the 103 mitogenomes alignment. 
bioRxiv preprint doi: https://doi.org/10.1101/190363; this version posted February 6,2019 . The copyright holder for this preprint (which was not certified by peer review) is the author/funder. All rights reserved. No reuse allowed without permission.

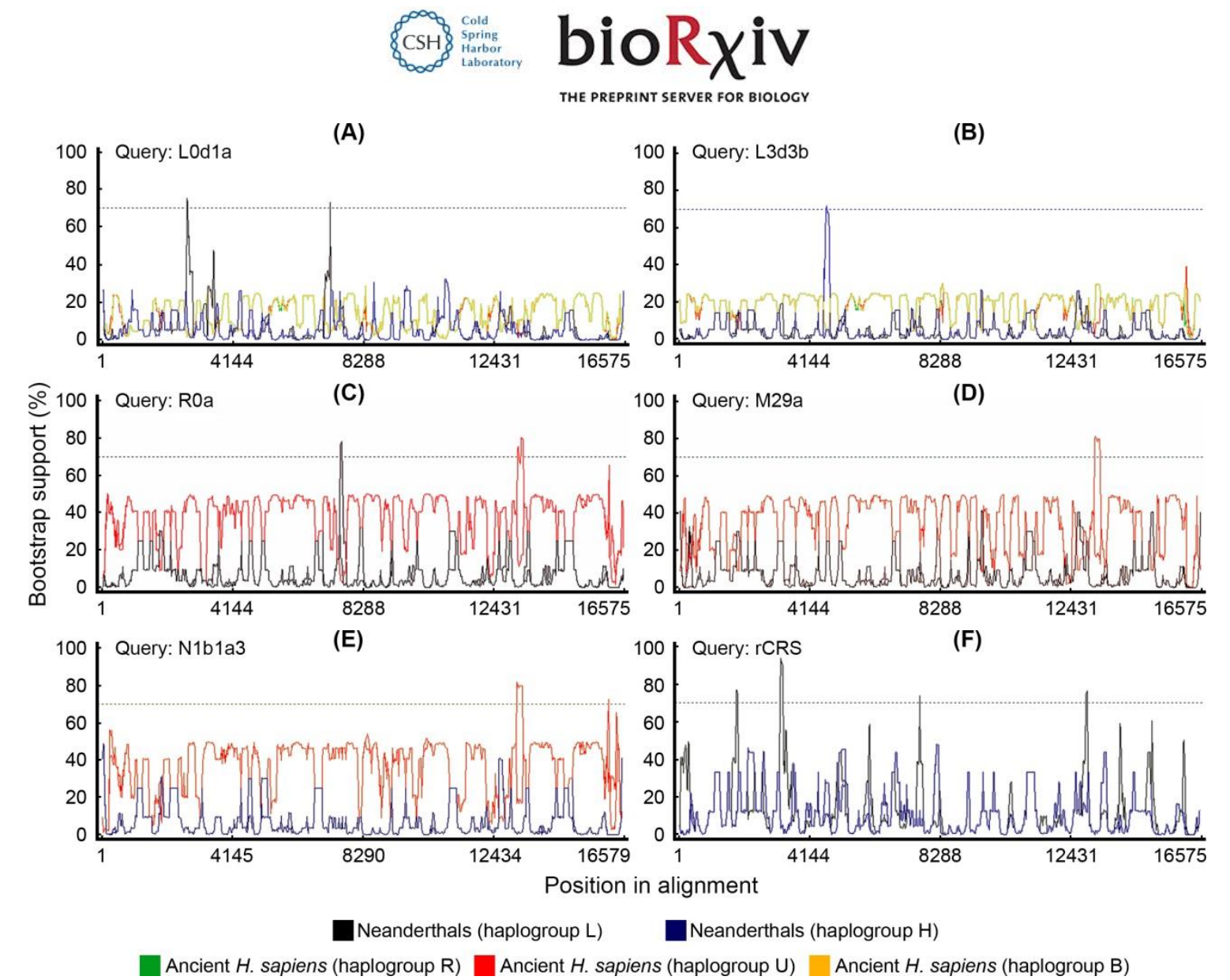

Fig. 6. Bootscan recombination analysis. Possible recombination points in were detected using different modern haplogroups as queries and Ancient H. sapiens or Neandertals as putative parental sequences. 